\title{
Normal language in abnormal brains ${ }^{1}$
}

\author{
Massimo Piattelli-Palmarini \\ (Department of Linguistics, University of Arizona)
}

In print in Neuroscience \& Biobehavioral Reviews (NBR) special issue 'The Biology of Language’ (Johan J. Bolhuis and Martin Everaert Eds.)

\section{Introduction}

More than one century and a half after Broca's pioneering studies of patients Leborgne and Lelong (Broca 1861, 1865), there is little doubt that, in the adult, specific brain lesions cause specific language deficits. Some of these language deficits can be remarkably specific, almost to the point of being unbelievable (Semenza, Zettin, \& Borgo, 1998) (loss of proper names only, mass nouns only, count nouns only, animal nouns only, names of landmarks only, names of Countries only, and several other stunning deficits). (For a recent review, see (Curtiss, 2013). Yet, brain localizations of linguistic functions are made problematic by several reported cases of normal language in spite of major brain anomalies, mostly, but not exclusively, occurring early in life. It is my opinion that these two horns of the dilemma deserve a closer analysis. ${ }^{2}$

\section{Hydrocephaly ${ }^{3}$}

John Lorber (1915-1996), a British pediatrician recognized by his work with spina bifida (see below) in Sheffield University, had the opportunity of attending a young man with macrocephaly (the result of microcephaly is an abnormal accumulation of cerebrospinal fluid in the brain). Although the boy had an IQ of 126 and had a first class honors degree in mathematics, he had "virtually no brain." Instead of the 4-5 centimeter thickness of cortical tissue in the normal brain, this young man had only a thin layer of mantle measuring one millimeter.

\footnotetext{
${ }^{1}$ I am indebted to my former students Catherine Dempsey, Heather Emady, Isaac Freitas and Melodie Yen for excellent summaries, insightful comments and extensive bibliographical searches. Their work helped me a lot in writing the present chapter.

${ }^{2}$ I am grateful to Thomas Bever, Susan Curtiss, Noam Chomsky, Martin Everaert and Stuart Hameroff for sending comments and suggestions on a previous draft.

${ }^{3}$ I first heard about one such case in a lecture in Paris, some 30 years ago, by the (then) celebrated British "antipsychiatrist” Ronald D. Laing. Among several problematic statements he made, one is hard to disagree with, even today: that there is a lot about the brain we do not understand.
} 


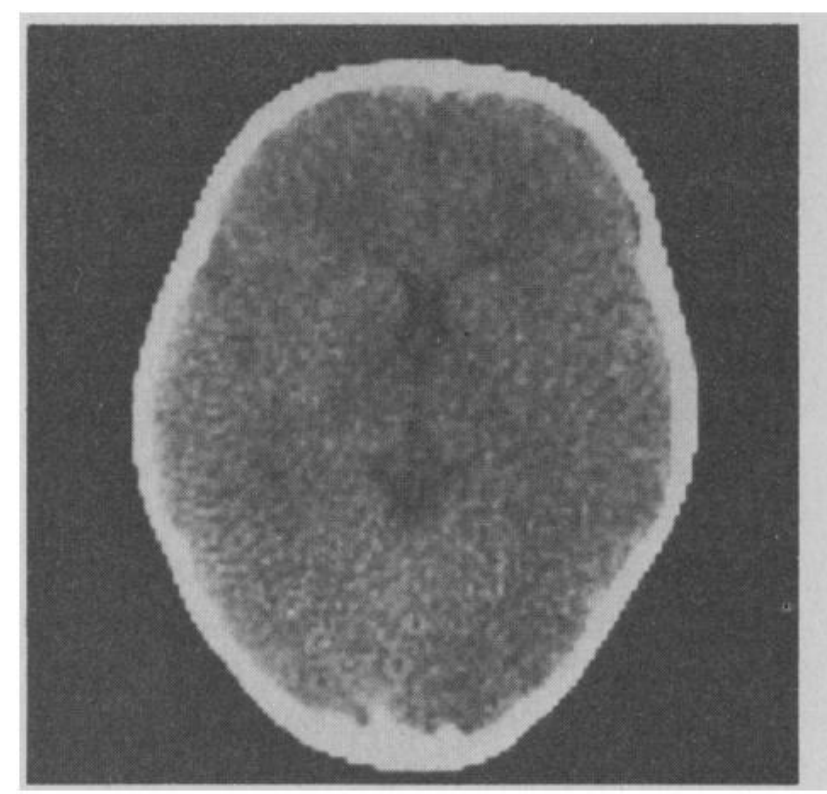

Normal brain

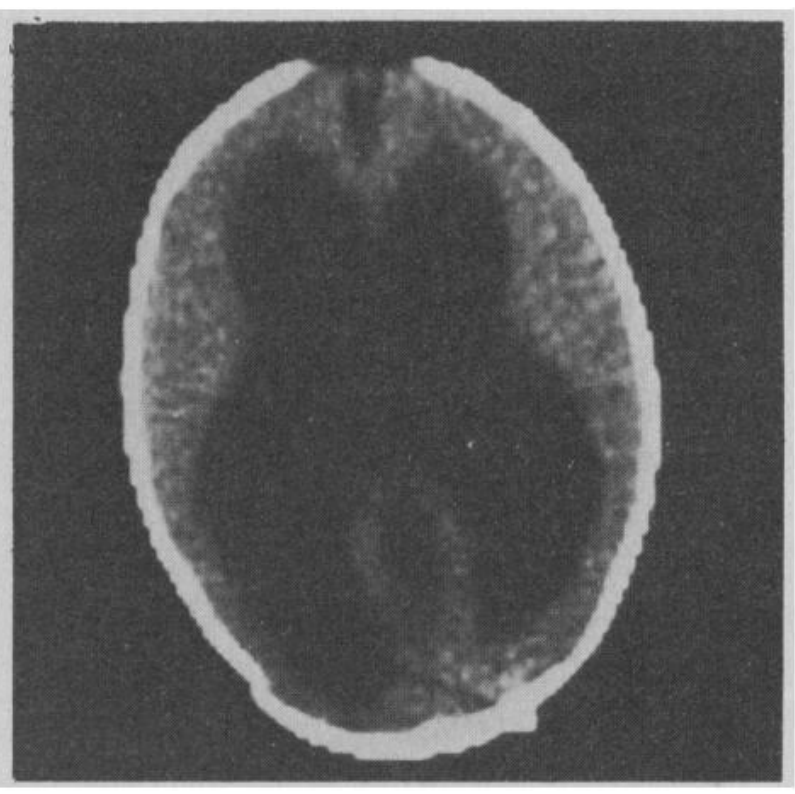

Hydrocephalus

Thus, Lorber thought, there should be a tremendous amount of redundancy or spare capacity in the brain. These ideas were shared with the scientific community in a pediatric conference in 1980. Later in the same year, his data and ideas were published by Roger Lewin in Science magazine. Both Lorber's talk at the conference and Lewin's article in Science have the provocative title "Is your brain really necessary?” (Lewin, 1980). More generally, after examining over 600 cases of brain scans of subjects with hydrocephaly, Lorber remarked that 50 per cent of the subjects in which the cerebro-spinal fluid fills 95 per cent of the brain had an IQ greater than 100 . The other half, though, were severely disabled. Lorber told Lewin that the cortex is probably responsible for a great deal less than most people imagine. Other neurologists disagreed, but the issue was left open and still is.

In hydrocephaly, the pressure of the liquid on the outer part of the brain and the consequent reduction in thickness takes place slowly and progressively, allowing (it appears) a slow and progressive restructuring of the nerve fibers. Sudden traumatic lesions have drastically different and much more devastating effects, at any age. Moreover, the primary disruption affects the white matter (the glias), rather that the grey matter (the neuronal fibers). A related clinical case, in which Lorber was also involved, is spina bifida.

\section{Spina bifida ${ }^{4}$}

A few years before, Lorber had been at the center of another polemic, when he advised against intense clinical treatment for some cases of children with spina bifida.

Spina Bifida is a neural tube defect associated with malformations of the spine and the brain. It is the most common severely disabling birth defect in the US, occurring 1 of every 2500 births per year (Centers for Disease Control, 2002). Recent research in structural neuro-imaging reflects that these children have profound dysmorphologies of brain development, in the cerebellum, midbrain,

\footnotetext{
${ }^{4}$ I am particularly indebted to Catherine Dempsey and Heather Emady for this section.
} 
corpus callosum, and posterior cortex (Fletcher et al. 2002). There are many forms of Spina Bifida, but Spina Bifida Mylomeningocele (SBM) is the most severe type, accounting for $90 \%$ of cases (McLone, 1992). SBM is associated with an open lesion -- a protrusion and herniation of the spinal cord. This lesion is most commonly located in the lumbosacral region is characterized by a central neural placode that is covered by a sac like membrane containing cerebrospinal fluid (e.g., the old term spina bifida cystica). SBM is unique as compared to other, less severe forms of SB as there is both cerebrospinal fluid and neural tissue present in the lower region of the spine in SBM and only cerebrospinal fluid in the latter. Hydrocephalus occurs in 95\% of children with Myelomeningocele.

Several publications, some recent, some not so recent, however, report selectively intact linguistic functions in these subjects, in spite of a range of other disabilities. Anderson and Clarke (1982) report the case of Michelle, who was "extremely talkative with an endearing manner, and made many spontaneous comments throughout the interview". Michelle is extremely physically handicapped, and she also has cognitive impairments: "Although articulate, Michelle has many marked learning problems and intellectually was one of the least able in the study". In other words, Michelle has mentally impaired cognitive functions, but her language is not affected. Michelle shows some of the symptoms of the "cocktail party syndrome."

Table 1 (adapted from an unpublished essay by Catherine Dempsey) summarizes these findings.

\begin{tabular}{|l|l|l|}
\hline \multicolumn{2}{|l|}{ Table 1. Summary of Intellectual Functioning of Individuals with SBM } \\
\hline Domain & Strengths & Weaknesses \\
\hline Intelligence & Verbal IQ & Performance IQ \\
\hline Memory & Rote & Reconstructive \\
\hline Attention & & Focused attention \\
\hline Language & Lexicon, syntax & Pragmatics \\
\hline Reading & Decoding & Comprehension \\
\hline Mathematics & Fact retrieval & Computations \\
\hline
\end{tabular}

In an early review, Anderson (1979) first described average IQ scores with higher verbal scores than nonverbal skills resulting in greater reading and spelling skills and much lower math skills. Children with shunts showed a characteristic pattern for language expression with good syntax and vocabulary scores, but poor ability to use language expressively (Fletcher et al., 2002). Barnes, Huber, Johnston \& Dennis (2007) reported learning difficulties, deficits in memory, comprehension of ongoing discourse and content-impoverished language, difficulties with making inferences, and problems with reading comprehension, and difficulties in the construction of meaning and pragmatic comprehension. Recently, Lomax-Bream et al., (2007) reported that the impact of lesion level and shunting significantly was related to growth in cognition and motor skills, but not language. Interestingly, there is evidence demonstrating that phonological and grammatical language is also intact.

From the table, one can see that IQ scores tend to show significantly lower scores on measures that are performance based; deficits on learning tasks are commonly reported; and on academic achievement tests, intact word recognition, but problems with writing, math computations and reading comprehension are frequently identified (Fletcher et al., 2002).

In summary, as Table 2 shows (also adapted from Catherine Dempsey), in the domain of language, in children with SBM, strengths are apparent in syntax and lexicon, and distinguished from 
weaknesses in meaning construction and pragmatic communication. These weaknesses may be interpreted as constructed in real time by inferential, integrative processes that require ongoing access to communication cohesion and coherence (Fletcher et al., 2002). Children with SBM appear to have language intact, with good vocabulary development, well-formed sentences and seem capable of understanding the essence, but only the essence, of conversational content.

Table 2: Summary of Language Strengths and Weaknesses of Individuals with SBM

\begin{tabular}{|l|l|l|l|}
\hline Syntax & Lexicon & $\begin{array}{l}\text { Meaning } \\
\text { Construction }\end{array}$ & $\begin{array}{l}\text { Pragmatic } \\
\text { Communication }\end{array}$ \\
\hline +Using word forms & +Using single words & $\begin{array}{l}\text {-Linking old and } \\
\text { new knowledge }\end{array}$ & -Verbose Language \\
\hline $\begin{array}{l}\text { +Understanding } \\
\text { sentence syntax }\end{array}$ & $\begin{array}{l}\text { +Understandings } \\
\text { single words }\end{array}$ & $\begin{array}{l}\text {-Making inferences } \\
\text { for coherence or } \\
\text { elaboration }\end{array}$ & $\begin{array}{l}\text {-Stereotyped } \\
\text { phrases poorly } \\
\text { matched to context }\end{array}$ \\
\hline & +Vocabulary & $\begin{array}{l}\text {-Text cohesion and } \\
\text { comprehension } \\
\text { problems }\end{array}$ \\
\hline
\end{tabular}

These children may have difficulty more generally with overall comprehension, problem-solving, and may use words not appropriately matched to context. The children with intact language, but impairment at the semantic level may be harder to identify. Interventions should attend to the use of language in different social contexts, to facilitate social adjustment. In addition, nearly all children with SBM have difficulties with pragmatic communication and meaning construction requiring flexible language processing. Therefore Lorber was right: drastic clinical intervention is not recommended in some cases of children with SBM.

Let's now have a look at another stunning case of normal language in an abnormal brain: hemispherectomy.

\section{Hemispherectomy ${ }^{5}$}

Hemispherectomy is a surgical procedure in which either the right or the left hemisphere is removed. Hemispherectomies are used as a last resort for patients whose seizures are global and resistant to all known drugs. (Weiner 2004; Shields 2004). When the procedure for hemispherectomy was first created, the entire hemisphere would be removed. This is known as an anatomic hemispherectomy. In more recent years, it has become more common to remove smaller regions; thus, it affects the patient's brains less. This is known as a functional or disconnection hemispherectomy. Susan Curtiss (personal communication) tells me that in her experience with close to 100 pediatric hemispherectomies, outcome depends on the specific epileptic disease, the presence or absence of cortical dysplasia, the health/state of the remaining hemisphere, the age at surgery (adult hemispherectomy and childhood hemispherectomy lead to very different outcomes, especially after left hemispherectomy) and sometimes side of surgery. If Rasmussen's encephalitis

\footnotetext{
${ }^{5} \mathrm{I}$ am indebted to Isaac Freitas for this section.
} 
(RE) is caught early enough and surgical intervention is early enough, RE has an excellent recovery prognosis ${ }^{6}$.

In fact, an interesting case has been succinctly reported in 2002 by J. Borgstein and C. Grootendorst, neurologists at the University Hospital in Amsterdam. After the removal of her left hemisphere, this 7-yer-old girl fully recovered her language abilities, becoming again fully bilingual in Dutch and Turkish.

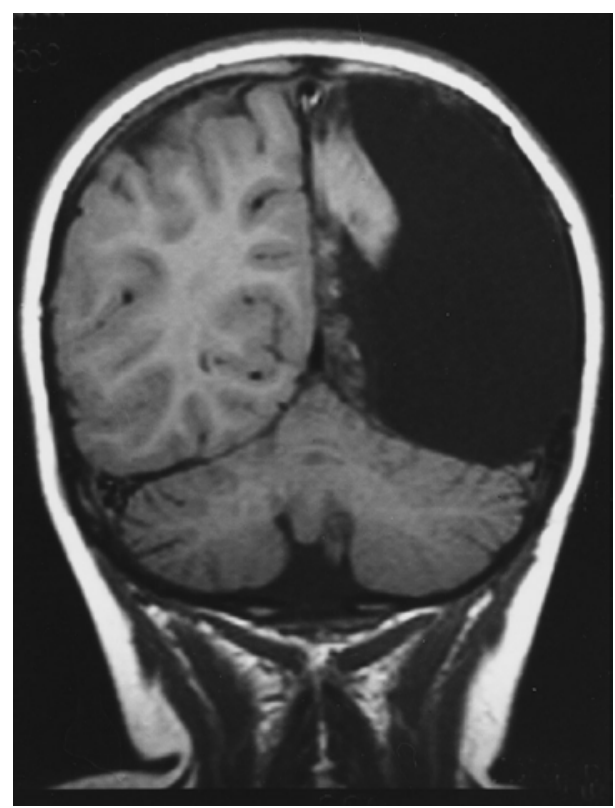

from Borgstein, J., \& Grootendorst, C. ( 2002). Clinical Picture: Half a Brain. The Lancet, 359 (February 9), 473.

The case is so described by these authors:

"This 7-year-old girl had a hemispherectomy at the age of 3 for Rasmussen syndrome (chronic focal encephalitis). Intractable epilepsy had already led to right-sided hemiplegia and severe regression of language skills. Though the dominant hemisphere was removed, with its language centres and the motor control for the left side of her body, the child is fully bilingual in Turkish and Dutch, while even her hemiplegia has partially recovered and is only noticeable by a slight spasticity of her left arm and leg. She leads an otherwise normal life.”

Curtiss and Schaeffer (1997) and then Curtiss, de Bode, and Mathern (2001) using the CYCLE (Curtiss and Yamada 1987), which covers comprehension and production of the core of English grammar, plus

\footnotetext{
${ }^{6}$ Sergey Avrutin did work on this in Utrecht, in a project "Language reorganization after hemispherectomy" http://www.uu.nl/en/research/neuroscience-and-cognition-utrecht/language-reorganization-following-cerebralhemispherectomy
} 
many additional language tests, assessing comprehension, production and judgment of a variety of grammatical structures, had already documented varying degrees of language recovery after hemispherectomy, signaling some cases of remarkable to total recovery. Boatman and colleagues (Boatman et al.,1999) had looked at 6 children who underwent left hemispherectomy for treatment of Rasmussen's encephalitis. Language testing included speech sound discrimination, single word comprehension (a modified version of the Token test), repetition and naming. One year after surgery these children's comprehension (mostly of words) was comparable with normals, while spoken language development remained significantly compromised in some cases (single words and telegraphic speech). Hence, an examination of this literature illustrates that at this point it is neither clear whether children who undergo hemispherectomy can be expected to evidence good language development, nor under what circumstances such a prognosis will occur.

The best cases show that, especially when administered at a young age, the right hemisphere is capable of fully "taking over" the linguistic functions normally located in the left hemisphere (e.g. Curtiss and De Bode 2003; De Bode et al. 2015). In some reported cases (Mariotti et al, 1998) there is an accompanying loss of visuospatial abilities, presumably due to a functional "invasion" of the visual regions by the language function.

While it might not seem possible for the adult mind to achieve the same degree of plasticity as a younger one, there is the case of E.C., a 47-year-old male, who had his left hemisphere removed due to a tumor. After the procedure, he underwent a phase where he had severe aphasia with comprehension of only simple commands. He gradually regained control of language, both in comprehension and expressing himself. It did take this man multiple years to recover language, implying that there is still plasticity in the brain, but that it is at a reduced rate among adults (Smith \& Burklund, 1966). Cases like this show that recovery of the language functions is not the exclusive property of very young brains. Surely, brain plasticity decreases over the years, but it does not disappear in later years.

Curtiss, de Bode and Mathern (2001) have analyzed post-surgery linguistic outcomes of 43 hemispherectomy patients operated on at UCLA. In their vast historical review of the topic, they make their motivation clear: "In our opinion, it is the study of language development posthemispherectomy -- the removal of an entire cortical hemisphere -- that best addresses the question of the linguistic potential of each hemisphere.” Their conclusion, after an accurate statistical, multi-factorial analysis of all these cases is: "Once we made etiology our focus, we found we were able to provide a single account for a wide variety of conflicting results which were otherwise neither predicted nor explained, in our own research and in the field as a whole. [...] Specifically, our current research now addresses the status of the remaining hemisphere as a primary factor defining language outcome, in accordance with previous suggestions in the literature.”

Curtiss and Schaeffer (2005), adopting an early version of Chomsky’s Minimalist Program (Chomsky 1993) make specific predictions as to which syntactic components are likely to be especially affected in different cases of hemispherectomy. The I(nflectional)-system (responsible, among others, for verbal conjugation) is expected to be differentially affected, or not affected. They say:

"First we hypothesize that the children who have undergone left-hemispherectomy and have only a right hemisphere, will evidence a greater error rate in use of I-system elements [such as $3^{\text {rd }}$ person verbal flection $-s, \mathrm{MPP}$ ] compared to the right hemispherectomies. Second, we hypothesize that the right hemispherectomied children, those with only a left hemisphere, will develop normal grammars, exhibiting normal developmental patterns with respect to the I-system, eventually attaining the adult I-system in the target language. Third, given the increasing evidence that even 
early child grammars, normal and abnormal, embody functional categories, we hypothesize that even in the course of protracted and impaired linguistic development, the left-hemispherectomied children will, nonetheless, develop grammars which contain the functional categories of I present in adult English.”

A detailed specification of the different components of the I-system (subject-verb agreement, tense marking on the verb) leads to specific tests for a sub-population of 13 hemispherectomised children of variable age, compared to a wider population of 20 righthemisphere and 20 left-hemisphere hemispherectomised subjects.

Their Table 2 summarizes the results, which are interpreted as being in favor of the hypothesis. In fact, they found consistently greater rate of I-system errors in the group of left hemispherectomies. This suppports the view that there is a predisposition for left hemisphere specialization for grammar and its development. The presence of at least some I-system structures in the speech of all of the children except one (MC) provides persuasive evidence that the human language faculty and its development is highly constrained, such that both child and adult grammars are consistently characterized by quite specific grammatical (UG) principles, instantiated in quite specific structures.

Table 2: \% Error for the I-system categories per child

\begin{tabular}{|c|c|c|c|c|c|c|c|c|c|c|}
\hline & child & $\begin{array}{l}\text { subj. } \\
\text { pron. }\end{array}$ & $\begin{array}{l}\text { aux/ } \\
\text { mod. }\end{array}$ & -ed & $-d$ & $-s$ & to & -en & $-n$ & -ing \\
\hline \multirow[t]{8}{*}{ left } & LB & 0 & 0 & $0 *$ & 0 & $0 *$ & 0 & - & 0 & 0 \\
\hline & GD & 3.6 & 8.3 & 12.5 & 9.1 & 8.33 & 5.6 & 0 & $20 *$ & 0 \\
\hline & JF & 33.3 & - & - & - & - & - & - & - & 0 \\
\hline & $\mathrm{JB}$ & 62.5 & 28.6 & 0 & - & - & 0 & - & $100^{*}$ & 0 \\
\hline & GG & 0 & 33.3 & 100 & 57.1 & - & 0 & - & $0^{*}$ & - \\
\hline & SM & 2 & 43.8 & $0 *$ & - & 66.7 & - & - & 0 & 25 \\
\hline & RP & - & $100 *$ & - & - & - & $100 *$ & - & - & 0 \\
\hline & MW & 33.3 & 0 & - & - & 0* & $100 *$ & - & - & - \\
\hline $\begin{array}{c}\text { mean } \\
\text { error \% }\end{array}$ & & 19.2 & 30.6 & 22.5 & 22 & 18.8 & 34.3 & 0 & 24 & 4.16 \\
\hline & & & & & & & & & & \\
\hline \multirow{5}{*}{ right } & SL & 1.47 & 3.57 & 4.35 & 0 & 0 & 0 & 0 & 4.76 & 0 \\
\hline & MC & 0 & 0 & 0 & 0 & 25 & 0 & 0 & 0 & 0 \\
\hline & JE & 0 & 0 & 0 & - & - & 0 & - & - & 0 \\
\hline & BB & 0 & 1.2 & 12.5 & 3.9 & 0 & 0 & 0 & - & 0 \\
\hline & MO & 1.3 & 1.9 & 33.3 & 5.6 & 7.1 & 0 & $0 *$ & - & 0 \\
\hline $\begin{array}{c}\text { mean } \\
\text { error \% }\end{array}$ & & 0.6 & 1.4 & 10 & 2.4 & 8 & 0 & 0 & 2.38 & 0 \\
\hline
\end{tabular}

subj. pron. = subject pronoun

aux $/ \bmod$. = auxiliary $/$ modal

-ed $\quad=$ regular past

-d = irregular past

*
$=$ out of 1 occurrence $-\mathrm{s}=3^{\text {rd }}$ person singular

to $=$ infinitival $t o$

-en $=$ regular past participle

-n = irregular past participle

-ing $=$ progressive or present

participle 


\section{Consequences and reflections}

This vast literature ${ }^{7}$ points to different degrees of brain plasticity and progressive reconfiguration, leaving several components of the language faculty uncompromised. These authors, from Lorber onwards, (see Curtiss 2013 for an ample review) suggest that there are specific language centers in the brain, but that their localization and function can be "taken over" by other centers, in the cases we have seen above. An explanation of this process is still lacking, but there are some considerations that can be offered.

Our brain is of course necessary, but possibly not all of the 100 billions of neurons in it are. An interesting suggestion of a possible vast redundancy comes from a prima facie unlikely source: the bees. ${ }^{8}$ Dyer et al. (2005) showed, with extremely careful tests, that the honey bees can successfully be trained to recognize individual human faces. The brain of a honeybee (Apis mellifera) occupies just a cubic millimeter and contains 960,000 neurons: less than a million. These neurons are, however, organized in specific and specialized compartments, just like the brain of vertebrates. Bees can be trained to discriminate among very complex visual stimuli, but their capacity to come to identify different human faces came as a surprise. In fact, as Dyer and colleagues stress, "the honeybee (Apis mellifera ) has not been exposed to evolutionary pressure for recognizing human faces but does have impressive pattern recognition and cognitive abilities that might facilitate the task.”

For our present purposes, this finding suggests that perhaps not all of the approximately 100 billion of neurons of the human brain are all necessary. Very subtle visual recognition and learning are shown to be supported by relatively few neurons. If there is vast redundancy, the cases we have seen above may begin to find an explanation. As Chomsky has repeatedly suggested in recent years, the very core of syntactic capacities (he compares them to a snowflake), unlike the complex task of externalizing their output, may well be restricted to very basic computations, requiring a limited number of neurons

A different, complementary, avenue of explanation may be found inside the neurons, in lattice polymers called microtubules, major components of the cell cytoskeleton proposed to process information, regulate cognition, encode memory and probably language as well ${ }^{9}$. The previously un-appreciated role of microtubules in guiding the direction and connectivity of the cone of nerve growth has recently been identified (Kahn \& Bass 2016). The presumption is that a cascade of signals regulate neuronal growth, prompting selective microtubule directional assembly, but such cascades have yet to be determined. Kahn and Bass conclude: “At present, there is little evidence that speaks to the signaling pathways by which environmental cues relevant to axon navigation might activate or deactivate particular motor proteins (and severing proteins) in functionally important regions of the growth cone to elicit polarized invasion of microtubules. The next frontier lies in elucidating these pathways to improve our understanding of the wiring of the nervous system during development. Progress on this frontier will hopefully provide new opportunities in the clinic for coaxing regenerating adult axons of the injured nervous system to re-navigate to their appropriate targets.”

Neuronal redundancy and the developmental role of microtubules in guiding the growth

\footnotetext{
${ }^{7}$ I can only report here a drastic selection, for a more comprehensive bibliography, see the papers cited.

${ }^{8}$ I am indebted to Giorgio Vallortigara for pointing me to this finding.

${ }^{9}$ I am indebted to Stuart Hameroff for many discussions and many publications by him and colleagues on the nature and role of microtubules. For an earlier comprehensive review, see (Hagan, Hameroff and Tuszynski 2000)
} 
and reconfiguration of the brain may well be, in the years to come, the keys to understand the perplexing phenomena we have sketched in the preceding pages (Allen, Haywood, Rajendran, \& Branigan, 2010).

Stuart Hameroff (personal communication) thinks that perhaps the answer is not in pathways of soluble signals. It seems more likely, or at least plausible that guidance and intelligence in axonal growth, neuronal development, cognition, memory, language and even consciousness are intrinsic to microtubules, and re-configuration of the nervous system (like normal configuration in the absence of injury or malformation) depends on microtubule-based information processing. If so, interesting avenues of positive interventions open up. Guiding the growth and reconfiguration of the brain may well be, in the years to come, enhanced by stimulation of microtubules, known to have resonances in terahertz, gigahertz and megahertz frequencies (Sahu et al, 2013a; 2013b, 2014), e.g. amenable to non-invasive stimulation by infra-red or ultrasound.

\section{REFERENCES}

Allen, M. L., Haywood, S., Rajendran, G., \& Branigan, H. (2010). Evidence for syntactic alignment in children with autism. Developmental Science, no-no. doi:10.1111/j.14677687.2010.01001.x

Anderson, Elizabeth M., and Lynda Clarke. Disability in Adolescence. London: Methuen, 1982.

Anderson E. (1979) Cognitive Deficits in Children with Spina Bifida and Hydrocephalus: A review of the literature. Educ Forward Trends. Jun;3(2):17-20.

Barnes MA, Huber J, Johnston AM, Dennis M. (2007) A model of comprehension in Spina Bifida Meningomyelocele: Meaning activation, integration, and revision. J Int Neuropsychol Soc. Sep;13(5):854-64.

Barnes M, Dennis M, Hetherington R (2004). Reading and writing skills in young adults with Spina Bifida and Hydrocephalus. J Int Neuropsychol Soc.Sep;10(5):655-63.

Boatman, D., Freeman, J., Vining, E., Pulsifer, M., Miglioretti, D., Minahan, R., Carson, B., Brandt, J., and McKhann, G. (1999). Language recovery after left hemispherectomy in children with late-onset seizures. Annals of Neurology, 46(4), 579 - 586.

Borgstein, J., \& Grootendorst, C. ( 2002). Clinical Picture: Half a Brain. The Lancet, 359 (February 9), 473.

Broca, Paul. "Perte de la parole, ramollissement chronique et destruction partielle du lobe antérieur gauche du cerveau." Bull Soc Anthropol 2.1 (1861): 235-238.

Broca, Paul. "Sur le siège de la faculté du langage articulé." Bulletins de la Société d'Anthropologie de Paris 6.1 (1865): 377-393. 
Byrne K, Abbeduto L, Brooks P.(1990) The language of children with Spina Bifida and Hydrocephalus: Meeting task demands and mastering syntax. J Speech Hear Disord.

Feb;55(1):118-23.

Centers for Disease Control and Prevention.(2002) Spina bifida and anencephaly prevalence-United States, 1991-2001. MMWR Morb Mortal Wkly Rep;51:9-11.

Chomsky, N. (1993) “ A Minimalist Program for linguistic theory.” In K. Hale and J. Keyser (eds.) The view from building 20. MIT Press, Cambridge, Massachusetts.

Cleveland Clinic. (2004) Functional Hemispherectomy. The Cleveland Clinic Health Information Center. http://www.clevelandclinic.org/health/healthinfo/docs/3400/3458.asp?index $=10217$

Curtiss, Susan, and Jeannette Schaeffer. "Syntactic development in children with hemispherectomy: The INFL-system." Proceedings of the 21st Annual Boston University Conference on Language Development. Vol. 2. 1997.

Curtiss, Susan, Stella de Bode, and Gary W. Mathern. (2001) "Spoken language outcomes after hemispherectomy: factoring in etiology." Brain and Language 79.3: 379-396.

Curtiss, S. and S. de Bode. (2003). How Normal is Grammatical Development in the Right Hemisphere Following Hemispherectomy? The RI Stage and Beyond. Brain and Language, 86, 193-206.

Curtiss, S. and Schaeffer, J. 2005. Syntactic development in children with hemispherectomy The I-, D-, and C-systems. Brain and Language, 94, 147-166.

Curtiss, S. and Yamada, J. 1987/2016. The Curtiss-Yamada Comprehensive Language Evaluation: The CYCLE. http://thecycletest.com/

Curtiss, S. (2013). Revisiting modularity: Using language as window to the mind. In M. PiattelliPalmarini \& R. C. Berwick (Eds.), Rich Languages from Poor Inputs (pp. 68-90). Oxford, UK: Oxford University Press.

De Bode, S., Smets, L. Mathern, G. W. \& S. Dubinsky (2015): Grammar by the isolated right: Syntax after dominant cerebral hemispherectomy; Epilepsy and Behavior 51, 33-39

Dennis M, Jewell D, Hetherington R, Burton C, Brandt ME, Blaser SE, Fletcher JM. (2008) Verb generation in children with spina bifida. J Int Neuropsychol Soc. Mar;14(2):181-91.

Dyer Adrian G., Christa Neumeyer and Lars Chittka (2005) Honeybee (Apis mellifera) vision can discriminate between and recognise images of human faces. The Journal of Experimental Biology 208, 4709-4714 
Fletcher JM, Barnes M, Dennis M. (2002) Language development in children with Spina Bifida. Semin Pediatr Neurol. Sep;9(3):201-8.

Fletcher JM, Francis DJ, Thompson NM, Davidson KC, Miner ME. (1992) Verbal and nonverbal skill discrepancies in Hydrocephalic children. J Clin Exp Neuropsychol Jul;14(4):593-609.

S. Hagan, S. R. Hameroff and J. A. Tuszy'nski (2000) Quantum Computation in Brain Microtubules? Decoherence and Biological Feasibility, in arXiv:quant-ph/0005025v1 4 May 2000.

Holck P, Nettelbladt U, Sandberg AD. (2009) Children with Cerebral Palsy, Spina Bifida and pragmatic language impairment: Differences and similarities in pragmatic ability. Res Dev Disabil. Sep-Oct;30(5):942-51

Kahn, Olga I. and Peter W. Baas (2016) Microtubules and Growth Cones: Motors Drive the Turn Trends in Neurosciences, July 2016, Vol. 39, No. 7 pp. 433-440.

Lewin, R. (1980). Is Your Brain Really Necessary? Science, 210 (4475 (Dec. 12)), 1232 - 1234.

Lomax-Bream L. E., Barnes M., Copeland K., Taylor H. B., Landry S. H. (2007) The impact of Spina Bifida on development across the first 3 years. Dev Neuropsychol. 31(1):1-20.

Lorber, John. (1981) "Is your brain really necessary?." Nursing mirror 152.18: 29-30.

Mariotti, P.; L. Iuvone, M. C. Silveri, and M. G. Torrioli. (1998). Linguistic and non-linguistic abilities in a patient with early left hemispherectomy. Neuropsychologia Volume 36 (12), pp.1303-1312

McLone D.G. (1992) Continuing Concepts in the Management of Spina bifida Pediatr Neurosurg.;18:254-256

Mohr JP. "Broca’s area and Broca's aphasia.” In: Whitaker H, editor. Studies in neurolinguistics. New York: Academic Press (1976): 201-236.

Pearson AM, Carr J, Hallwell MD.(1988) The handwriting of children with Spina Bifida. Z Kinderchir. Dec;43 Suppl 2:40-2.

Sahu et al (2013a) Biosens. Bioelectron. 47: 141-148.

Sahu et al (2013b) Appl. Phys. Lett. 102: 123701.

Sahu et al (2014) Scientific Reports 4:7303-1 DOI:10.1038/srep07303, 
Semenza, C., Zettin, M., \& Borgo, F. (1998). Names and identification: An access problem. Neurocase, 4(1), 45-53. doi:10.1080/13554799808410606

Shields, D. W. (2004) Surgical treatment of refractory epilepsy. Current Treatment Options in Neurology October 2004, Volume 6, Issue 5, pp 349-356

Smith, A., and C. W. Burklund. (1966). Dominant Hemispherectomy: Preliminary Report on Neuropsychological Sequelae (in Reports). Science, New Series, Vol. 153, 3741 pp. 1280-1282.

Weiner HL.(2004) Tuberous sclerosis and multiple tubers: localizing the epileptogenic zone. Epilepsia. 2004;45(supplement 4):41-42. 